\title{
A new species of Nemopalpus Macquart (Diptera, Psychodidae) from Brazil
}

\author{
Claudiney Biral dos Santos ${ }^{1,2}$, Aloísio Falqueto² \& Freddy Bravo ${ }^{3}$
}

\begin{abstract}
${ }^{1}$ Núcleo de Entomologia e Malacologia da Secretaria de Estado da Saúde do Estado do Espírito Santo, Brazil - NEMES. Avenida Marechal Campos 1468, 29040-090 Vitória-ES, Brazil. claudiney@ppgcf.ufes.br

${ }^{2}$ Unidade de Medicina Tropical, Universidade Federal do Espírito Santo, Av. Marechal Campos 1468, 29040-090 Vitória-ES, Brazil. falqueto@npd.ufes.br ${ }^{3}$ Departamento de Ciências Biológicas, Universidade Estadual de Feira de Santana, Av. Universitária s/n, 44031-460 Feira de Santana-BA, Brazil. fbravo@uefs.br
\end{abstract}

\begin{abstract}
A new species of Nemopalpus Macquart (Diptera, Psychodidae) from Brazil. Nemopalpus parvus sp. nov. collected in the Atlantic rainforest of the state of Espírito Santo, in southeastern Brazil, is described and illustrated.
\end{abstract}

KEYWORD. Atlantic rainforest; Bruchomyiinae; Insecta; moth-flies; Neotropical region.

The genus Nemopalpus Macquart, one of the three genera of Bruchomyiinae (Psychodidae), is worldwide distributed with 41 extant species, 28 of them from the Neotropical region (Curler \& Jacobson 2012). In Brazil, 14 species of Nemopalpus have been recorded with three species described from the Atlantic rainforest of the state of Espírito Santo: $N$. brejetubensis, N. capixaba and N. espiritosantensis (Santos et al. 2009; Curler \& Jacobson 2012). In this paper, one new species from the Atlantic rainforest of Espirito Santo is described and illustrated.

\section{MATERIAL AND METHODS}

The specimens studied were collected between 2008 and 2011 with CDC (Centers for Disease Control) light traps in different localities of Espírito Santo state, in southeastern Brazil. All these localities are within the Atlantic rainforest domain, with coordinates ranging between latitudes $13^{\circ} 07^{\prime}-$ $20^{\circ} 56^{\prime} \mathrm{S}$ and longitudes $38^{\circ} 52^{\prime}-41^{\circ} 52^{\prime} \mathrm{W}$. The specimens, previously preserved in $70 \%$ alcohol, were treated with $10 \%$ $\mathrm{KOH}$ and mounted in Canada balsam. All measurements are in $\mathrm{mm}$. Morphological terminology for Diptera follows that of Cumming \& Wood (2009). The type specimens are deposited in the Entomological Collection Prof. Johann Becker of the Museu de Zoologia da Universidade Estadual de Feira de Santana, Brazil (MZFS).

\section{TAXONOMY}

\section{Nemopalpus parvus Santos, Falqueto \& Bravo, sp. nov.}

(Figs. 1-6)

Diagnosis. Male.Wing with crossvein r-m on same level as median fork; $\mathrm{R}_{2}$ longer than $\mathrm{R}_{2+3} ; \mathrm{M}_{2}$ incomplete; abdominal pleurites without sclerites bearing long hairs; segments 6 and 7 unmodified; gonocoxite with small median setose pro- tuberance; gonostylus ending at curved tapering apex; parameres blade shaped with short spiniform bristles at the apex.

Description. Male. Length from thorax to the posterior end of terminalia: $4.2-4.6 \mathrm{~mm}(\mathrm{n}=2)$. Eyes separated by approximately 3.0 facet diameters; frontal area with 13-20 seta alveoli. Antenna incomplete only 13 flagellomeres present, $14^{\text {th }}$ provably lost in preparation; length of flagellomeres $2+3$ combined 1.4 times the length of flagellomere 1; pair of ascoids present, bifurcated. Palpus formula $(1+2: 3: 4: 5)=1.0: 0.9: 1.2: 3.0$; sensilla absent on second and third segment of palpus; apical segment striated (Figs. 1, 2). Wing length: 3.4-3.8 mm $(\mathrm{n}=2)$. Sc ending after level of radial fork, reaching $C$; crossvein sc-r reaching $\mathrm{R}_{1} ; \mathrm{R}_{2+3}$ shorter than $\mathrm{R}_{2}$; base of $\mathrm{R}_{5}$ not reaching $\mathrm{R}_{4}$ and without spur; crossvein $\mathrm{r}-\mathrm{m}$ incomplete, not reaching $\mathrm{M}$, on same level as radial and median forks; $\mathrm{M}_{2}$ incomplete, not reaching $M_{1}$ (Fig. 3). Abdominal pleurites without sclerites bearing long hairs; segments 6 and 7 unmodified. Male terminalia: hypandrium fused to gonocoxite; gonocoxite longer than ejaculatory apodeme with small median setose protuberance (Fig. 6); gonostylus short, 0.75 times the length of gonocoxite, ending at curved tapering apex; aedeagus bifurcated with blades apically divergent; pair of parameres present, blade-shaped with small and strong bristles at apex, 0.75 times the length of gonocoxites; ejaculatory apodeme narrow dorsally, slightly clavate laterally (Figs. 5, 6); epandrium longer than wide, trapezoidal, wider basally than apically (Fig. 4); cerci subelliptical in lateral view (Fig. 5), subtriangular in ventral view (Fig. 4); hypoproct lobe-like, rounded at apex (Fig. 4).

Female. Unknown.

Etymology. From the Latin parvus, short, small, referring to the short protuberance of the gonocoxite.

Type material. Holotype: male, Brazil, Espírito Santo, Cariacica municipality, Reserva Biológica Duas Bocas, $20^{\circ} 28^{\prime}$ 'S, 4046'W, 03.X.2008, 

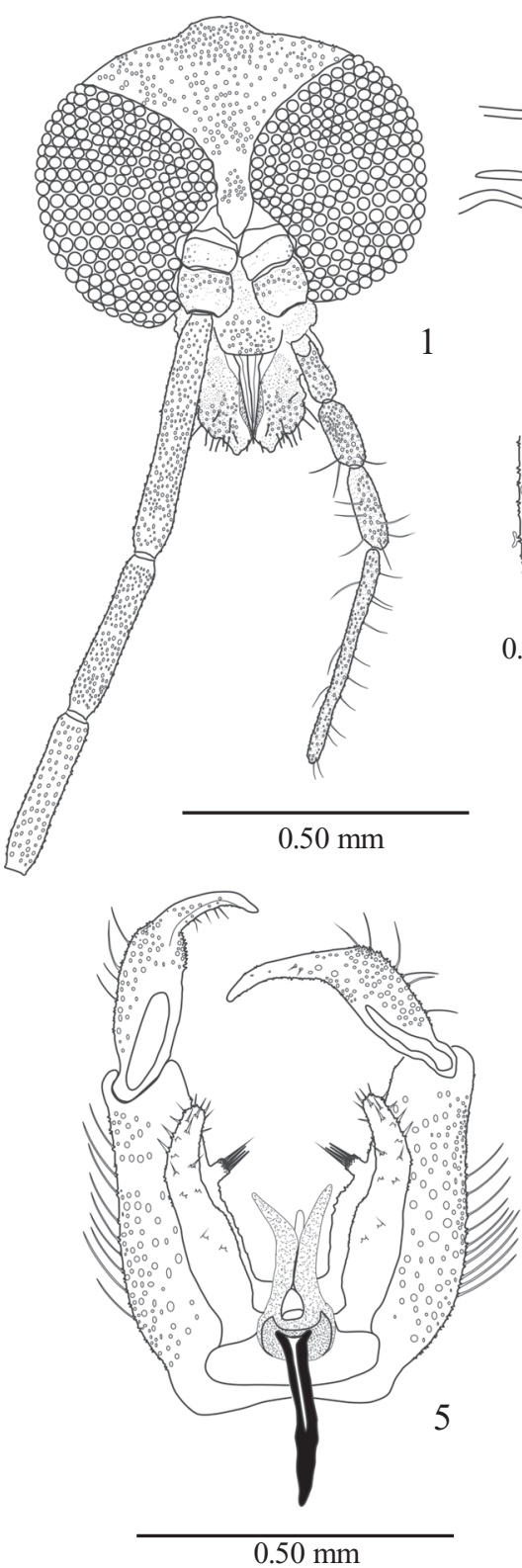
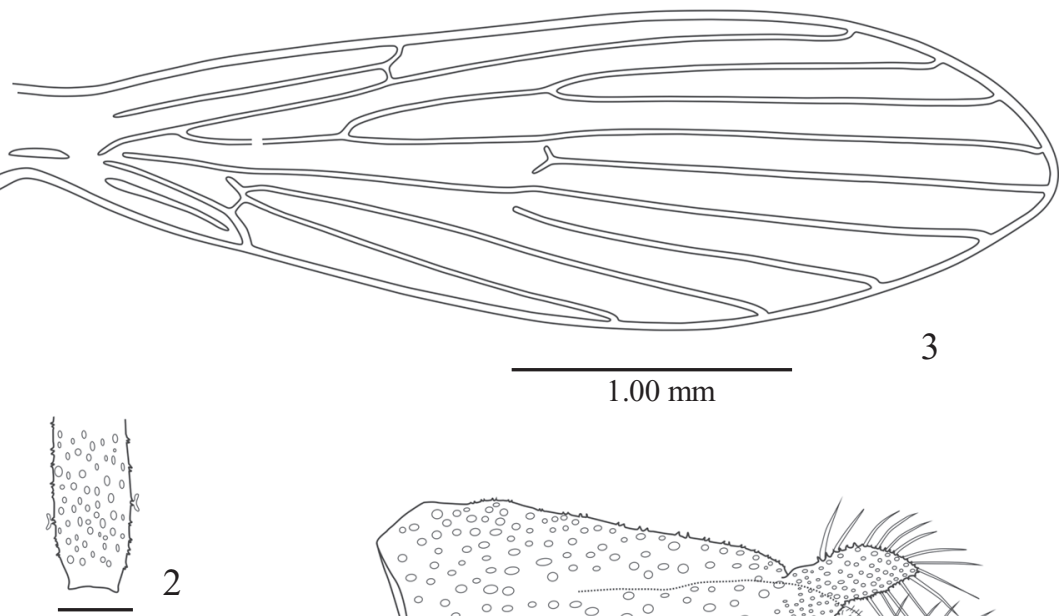

$0.05 \mathrm{~mm}$
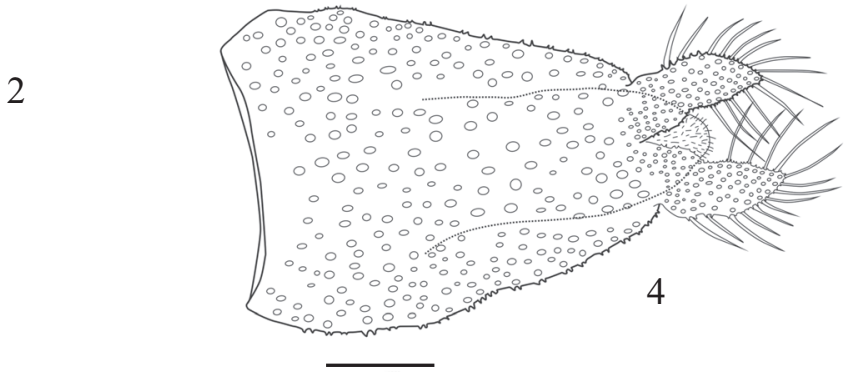

$0.25 \mathrm{~mm}$

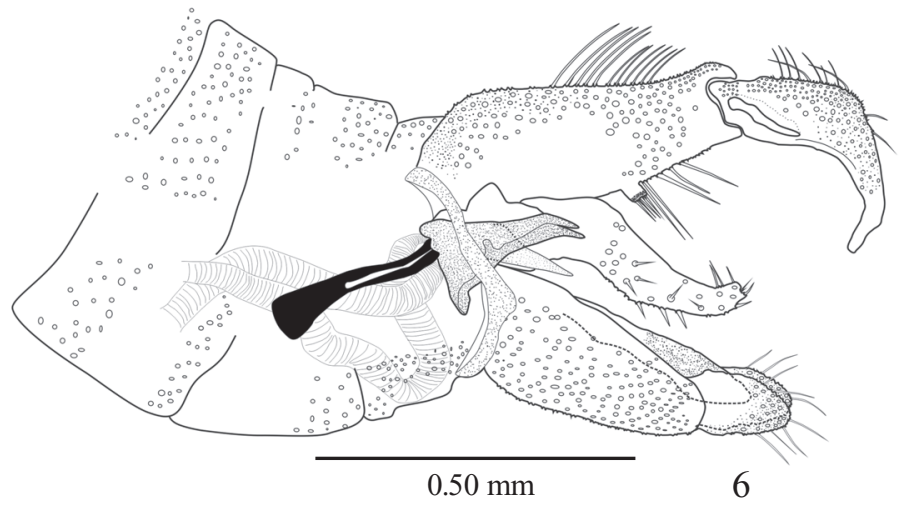

Figs. 1-6. Nemopalpus parvus Santos, Falqueto \& Bravo, sp. nov., holotype male. 1, head; 2, ascoid; 3, wing; 4, epandrium, cerci and hypoproct, ventral view; 5 , terminalia ventral view; 6 , terminalia,lateral view.

Santos, C. B. col. (MZFS). One male paratype, Brazil, Espírito Santo, Santa Teresa municipality, Reserva Biológica Augusto Ruschi, 1954'S, 40³3’W, 16.XII.2011, Santos, C. B. col. (MZFS).

Remarks. In the key to males of New World Nemopalpus of Quate \& Alexander (2000), the new species N. parvus is grouped with other species of the genus that has a crossvein r-m basal of, or on same level as median fork; the abdominal pleurites without sclerites bearing long hairs; and segments 6 and 7 unmodified. The new species differs from that group of species cited in the key of Quate \& Alexander (2000) because $R_{2+3}$ is shorter than $R_{2}$ while all other species have a vein $R_{2}$ shorter than $R_{2+3}$.

Other Neotropical species described after the work of Quate \& Alexander (2000), N. capixaba Santos, Falqueto \&
Alexander, N. espiritosantensi Santos, Falqueto \& Alexander, N. stuckenbergi Wagner, N. amazonensis Wagner \& Stuckenberg, N. cancer Wagner \& Stuckenberg and N. spinosus Bravo \& Barata possess, too, a vein $\mathrm{R}_{2}$ shorter than $\mathrm{R}_{2+3}$, (Santos et al. 2009; Wagner \& Stuckenberg 2012; Bravo \& Barata 2012), therefore differing from the new species. Moreover, $N$. similis Wagner \& Stuckenberg posses a group of ornamental setulae on abdominal segments 6 and 7 (Wagner \& Stuckenberg 2012) and thus it can be differentiated from $N$. parvus sp. nov. because in this latter species these abdominal setulae are absent. Finally, N. parvus sp. nov. differs from N. brejetubensis Santos, Falqueto \& Alexander because the latter possesses the distal part of the gonostylus directed downwards (Santos et al. 2009), while it is straight in the former. 


\section{ACKNOWLEDGMENTS}

We are grateful to Instituto Brasileiro do Meio Ambiente e dos Recursos Naturais Renováveis (IBAMA) (n²5517-1) for permission to collect in the Reserva Biológica Augusto Ruschi. F.B. received a research grant from CNPq (305055/2012-7).

\section{REFERENCES}

Bravo, F. \& Barata, R.A. 2012. A new species of Nemapalpus Macquart (Diptera, Psychodidae, Bruchomyiinae) from caverns in Minas Gerais State in southeastern Brazil. Zootaxa 3164: 64-68.

Curler, G.R. \& Jacobson, A.J. 2012. New species of Psychodidae (Diptera) from Australasia, with a checklist of the world species of Bruchomyiinae and Sycoracinae. Zootaxa 3552: 43-65.

Cumming, J.M. \& D.M. Wood. 2009. Adult morphology and terminology, p. 9-50. In: Brown, B.V.; Borkent, A.; Cumming, J.M., Wood, D.M., Woodley, N.E. \& Zumbado, M.A. (eds.). Manual of Central American Diptera, volume 1, Ottawa, National Research Council Press, xi+714 p. Quate, L.W. \& Alexander, J.B. 2000. Synopsis of the New World Nemapalpus (Diptera, Psychodidae, Bruchomyiinae) with description of four new species. Annals of the Entomological Society of America 93: 185-193.

Santos, C.B., Falqueto, A. \& Alexander, B. 2009. Description of three new species of Nemapalpus (Diptera, Psychodidae, Bruchomyiinae) from Atlantic Forest in southeastern Brazil. Zootaxa 2264: 58-64.

Wagner, R. \& Stuckemberg, B.R. 2012. New fossil and extant species of Nemopalpus Macquart (Diptera; Psychodidae; Bruchomyiinae). African Invertebrates 53: 355-367. 